\title{
Comparison of Visual and Multispectral Radiometric Disease Evaluations of Cercospora Leaf Spot of Sugar Beet
}

\author{
K. Steddom, Texas Agricultural Experiment Station, Amarillo, TX 79106; M. W. Bredehoeft, Southern Minnesota \\ Beet Sugar Cooperative, Renville, MN 56284; M. Khan, North Dakota State University and University of Minne- \\ sota, Fargo, ND 58105; and C. M. Rush, Texas Agricultural Experiment Station, Amarillo, TX 79106
}

\begin{abstract}
Steddom, K., Bredehoeft, M. W., Khan, M., and Rush, C. M. 2005. Comparison of visual and multispectral radiometric disease evaluations of Cercospora leaf spot of sugar beet. Plant Dis. 89:153-158.

Visual assessments of disease severity are currently the industry standard for quantification of the necrosis caused by Cercospora beticola on sugar beet (Beta vulgaris) leaves. We compared the precision, reproducibility, and sensitivity of a multispectral radiometer to visual disease assessments. Individual wavebands from the radiometer, as well as vegetative indices calculated from the individual wavebands, were compared with visual disease estimates from two raters at each of two research sites. Visual assessments and radiometric measurements were partially repeated immediately after the first assessment at each site. Precision, as measured by reduced coefficients of variation, was improved for all vegetative indices and individual waveband radiometric measures compared with visual assessments. Visual assessments, near-infrared singlewaveband reflectance values, and four of the six vegetative indices had high treatment $F$ values, suggesting greater sensitivity at discriminating disease severity levels. Reproducibility, as measured by a test-retest method, was high for visual assessments, single-waveband reflectance at $810 \mathrm{~nm}$, and several of the vegetative indices. The use of radiometric methods has the potential to increase the precision of assessments of Cercospora leaf spot foliar symptoms of sugar beet while eliminating potential bias. We recommend this method be used in conjunction with visual disease assessments to improve precision of assessments and guard against potential bias in evaluations.
\end{abstract}

Additional keywords: Cropscan, remote sensing

Cercospora leaf spot of sugar beet (Beta vulgaris L.), caused by Cercospora beticola Sacc., is the most damaging foliar disease in the Minnesota and North Dakota sugar-beet-growing region. In 2000, under moderate disease levels, losses of 2 to 3 tons/acre and up to $30 \%$ in recoverable sucrose were reported by Khan et al. (14). Cercospora leaf spot of sugar beet is a polycyclic disease that varies in severity due to weather conditions (33). During periods of warm, wet, humid conditions, conidia of the fungus infect leaves and cause small necrotic lesions. Under favorable environmental conditions, necrotic lesions expand and coalesce to cover large areas of the leaf and eventually can defoliate the entire plant, requiring the plant to regrow leaves. In the sugar-beet-growing

Corresponding author: K. Steddom

E-mail: k-steddom@tamu.edu

This work was funded by the Minnesota and North Dakota Sugarbeet Research and Extension Board and the Texas Precision Agriculture Legislative Initiative.

Accepted for publication 15 September 2004.

DOI: 10.1094/PD-89-0153

(C) 2005 The American Phytopathological Society regions of Minnesota and North Dakota, Cercospora leaf spot tends to occur annually from July through September.

Cercospora leaf spot of sugar beet is managed by planting moderately resistant cultivars, cultural practices that reduce primary inoculum, and multiple applications of fungicides. In 2000, the Southern Minnesota Beet Sugar Cooperative reported an average of four fungicide applications per field at a cost of approximately $\$ 66.40$ per acre for management of Cercospora leaf spot (12). Resistance to benzimidazole fungicides, first reported in 1981 (4), has become widespread in this region (32). Resistance to triphenyltin hydroxide first was reported in 1995 (5) and grew to levels as high as $62 \%$ by 2002 in some factory districts of the MinnesotaNorth Dakota sugar-beet-growing area (32). Due to the high cost of control, and the importance of monitoring efficacy of fungicide treatments and pathogen populations for development of resistance, several fungicide trials are established throughout the sugar-beet-growing regions annually. These trials are separated by large distances, requiring management and visual evaluations to be done by different researchers. The variability among ratings from different researchers makes it difficult to relate results among locations. A predictive epidemiological model has been developed and implemented throughout the region (33) to aid growers in managing disease levels. In order to improve this model, objective disease data from several locations are required. The variability among researchers and locations makes the use of visual assessments questionable for this purpose. In addition, there is growing demand from growers and industry to use methods that are perceived to be free from bias, especially for evaluation of high-cost proprietary material such as fungicides or seed varieties.

An appropriate disease assessment method should be accurate, precise, and reproducible (6). Accuracy is the difference between an observation and the true value of that parameter. Precision is the variation among a group of observations. The definition of reproducibility inferred from Shokes et al. (29) is the variation between two sets of observations taken at different times, whereas Campbell and Madden (6) expand this to include variation among different observers and different days. Any measurement includes some error; therefore, accuracy is difficult to assess in the absence of a universally acceptable standard to use as the true value. Precision can be estimated by comparing variance of different methods through coefficients of variation (CVs) when the same experimental units are assessed with each method. Sherwood et al. (28) showed that visual disease assessments of Stagonospora leaf spot of orchardgrass had high CVs and were not precise. The use of $\mathrm{CV}$ to estimate the variance of methods with different scales is preferable because $\mathrm{CV}$ is unitless and, therefore, resistant to scale effects (31). Reproducibility can be estimated with a test-retest methodology as demonstrated by Shokes et al. (29). Their test-retest method consists of evaluating disease twice, then measuring the correlation between the independent evaluations. In the absence of a method defined as accurate, the ability of a method to differentiate among treatments that generate a gradient of disease severity can be used along with precision and reproducibility to identify appropriate disease assessment methods. We have termed this measure sensitivity.

Visual assessments have been criticized for a lack of precision and are largely qualitative and subjective measures 
$(19,23,28,29)$. There are several alternative evaluation methods that have been shown to be more accurate and precise than visual assessments, including counting the number of abscessed leave in peanuts (29), manual image analysis of individual leaves (28), and computerized image analysis of whole plots (23). Unfortunately, these alternatives are too difficult, complex, or time consuming to be effectively used for the routine evaluations required for Cercospora leaf spot of sugar beet. Measurement of leaf reflectance with radiometers as suggested by Sharp et al. (27) is a viable option.

Remote sensing has been used for many years to assess the severity of plant diseases. Nilsson (19) provided a review of the history and methods of using remote sensing going back to the use of nearinfrared film in the 1920s. Jackson (11) described the theory behind remote sensing methods, focusing on their application to detect plant stress. The use of radiometers to assess disease severity is well established in the field of plant pathology and has been applied effectively on wheat (27), barley (20), rice (17), turfgrass $(23,26)$, peanuts (21), watermelon (2), alfalfa (24), and sugar beet (30). Nutter et al. (23) showed that radiometric assessments were more accurate and precise than visual assessments. Nutter et al. (24) showed that radiometric evaluations of alfalfa foliar diseases had lower CVs than visual estimates of disease, suggestive of greater precision. This is possible because leaves strongly reflect near-infrared light while chlorophyll strongly absorbs red light, creating a sharp rise in reflectance from near zero in the red region to near $50 \%$ in the near infrared (11). Soils and necrotic tissue do not have this sharp differentiation. Vegetative indices take advantage of this to accurately quantify photosynthetic tissue in the presence of necrotic tissue or soil (1). Guan and Nutter (10) reported that radiometric leaf reflectance was affected by solar intensity, sun angle, leaf wetness, and sensor height, and that radiometric assessments may be highly variable due to these environmental factors. However, they only considered single-waveband values in their assessments and not vegetative indices. Vegetative indices combine the information from multiple spectral bands to factor out the effects of variability in solar intensity and sun angle $(1,19)$. Vegetative indices have been developed to measure a number of agricultural parameters, such as canopy density $(1,3,8)$ and canopy pigment content $(3,7,9)$.

The objectives of this study were to compare the precision, sensitivity, and reproducibility of radiometric evaluations of disease severity to visual evaluations using an industry standard disease scale, and to determine whether the use of vegetative indices would improve the precision, sensitivity, and reproducibility of radiometric evaluations over single-waveband reflectance values.

\section{MATERIALS AND METHODS}

Field trials. Evaluations were performed on plots at two fungicide trials that provided the wide range of Cercospora leaf spot disease severity levels required for this study. The Willmar, $\mathrm{MN}$ site $\left(45.11^{\circ} \mathrm{N}\right.$, $95.04^{\circ} \mathrm{W}$ ) was described in detail in Khan et al. (15). The Willmar site was planted on 13 May 2002 with the Cercospora leaf spot-susceptible sugar beet cv. Beta 4705 and inoculated with infested sugar beet leaf residue, resulting in high disease levels. There were 34 fungicide treatments with four replications arranged in a randomized complete block design. Due to time constraints, only the first three replicate blocks were used for this study. The study was repeated at a second site in St. Thomas, ND $\left(48.62^{\circ} \mathrm{N}, 97.45^{\circ} \mathrm{W}\right)$, described in Khan and Khan (13). The St. Thomas site was planted on 14 May 2002 with the Cercospora leaf spot-susceptible cv. HH Agate and the tolerant cv. Crystal 222 and received only natural sources of inoculum, resulting in only moderate disease levels. There were five fungicide treatments with four replications arranged in a split-block design with the two cultivars as the main plot. For consistency between sites, only the data from the susceptible cultivar was used, resulting in a total of 20 plots at this site, and reducing the experimental layout to a randomized complete block design. At both sites, the treated area of each plot was four rows wide $(2.2 \mathrm{~m})$ and $10.6 \mathrm{~m}$ long. Visual and radiometric evaluations were performed at the same time, approximately 1 month before harvest on 3 September 2002 at St. Thomas and 4 September 2002 at Willmar.
At this time, sugar beet plants had fully developed canopies, and there were no visible fungicide residues present on the leaves that might interfere with visual or radiometric evaluations. At harvest, the middle two rows of each plot were harvested and yield in kilograms of extractable sucrose per hectare was calculated from the weight of roots harvested and the concentration of sucrose in the root tissue. The objectives of this article concern the comparison of evaluation methods; therefore, further details of the fungicide trials will not be reported but can be found in their original citations $(13,15)$.

Visual assessments. To avoid bias, each plot was coded with a plot number that was independent of the treatment applied to the plots. Each site was rated by the researcher who maintained the site, resulting in one local rater for each location. Each site also was rated by a visiting researcher. To assess the reproducibility of each method, each site was evaluated by the same researchers a second time immediately following the first evaluation. The plots at both sites were rated using an industry standard disease scale, the Kleinwanzlebener Saatzucht (KWS) scale (16), a continuous scale ranging from 1 to 9 , where $1=$ no leaf spot symptoms, 3 = fungal lesions can be found on the outer leaves, $5=$ lesions have coalesced to form small areas of necrotic leaf tissue, $7=$ older leaves have shriveled and died and disease has spread to the inner leaves, and $9=$ almost all leaves have died and new leaves are starting to emerge. The raters observed disease severity over the whole plot and assigned a single value for the plot based on the predominant level of disease within the plot. All ratings were made in full sun, which made it easier to visualize the small necrotic lesions of Cercospora.

Radiometric readings. A multispectral field radiometer (MSR16; CropScan, Inc. Rochester, MN) was used at both research sites to measure the spectral reflectance of the canopy for radiometric evaluations at the same time raters performed visual evaluations. The radiometer operator did not participate in visual evaluations. The multispectral radiometer measures solar light intensity and canopy reflected light intensity simultaneously in nine fixed wavebands (Table 1). The radiometer soft-

Table 1. Spectral characteristics of the CropScan MSR16 radiometer

\begin{tabular}{lcll}
\hline Waveband $^{\mathbf{z}}$ & Range $\mathbf{( n m )}$ & Color & \multicolumn{1}{c}{ Properties } \\
\hline $\mathrm{R}_{460}$ & $456-463$ & Blue & Absorbance by chlorophyll and atmospheric water \\
$\mathrm{R}_{510}$ & $506-514$ & Green & Low absorbance by chlorophyll hence green color of leaves \\
$\mathrm{R}_{559}$ & $555-564$ & Green & Low absorbance by chlorophyll hence green color of leaves \\
$\mathrm{R}_{610}$ & $607-617$ & Red & High absorbance by chlorophyll \\
$\mathrm{R}_{661}$ & $655-666$ & Red & High absorbance by chlorophyll \\
$\mathrm{R}_{710}$ & $702-714$ & Red & High absorbance by chlorophyll \\
$\mathrm{R}_{760}$ & $746-774$ & Near-infrared & High reflectance by air-water interfaces in leaf mesophyll \\
$\mathrm{R}_{810}$ & $797-829$ & Near-infrared & High reflectance by air-water interfaces in leaf mesophyll \\
$\mathrm{R}_{935}$ & $790-1,080$ & Near-infrared & High reflectance by air-water interfaces in leaf mesophyll \\
\hline
\end{tabular}

${ }^{\mathrm{z}}$ Single-waveband reflectance at nanometers indicated (460, 510, and so on). 
ware divides the canopy reflected light intensity by the solar light intensity to provide the percentage of light reflected $(0$ to $100 \%$ ) for each waveband. This value is termed reflectance. The sensor has a $28^{\circ}$ field of view and was set at $2 \mathrm{~m}$ above the canopy perpendicular to the ground to give a 1-m-diameter field of view. Three scans were taken equidistantly along the length of each plot, avoiding the edges. These scans later were averaged to give a single radiometric reading for the whole plot. As with the visual assessments, radiometric assessments were repeated a second time immediately after taking the first set of readings by the same operator. Canopy reflectance was used to calculate vegetative indices for each plot. The reflectance of bare soil immediately adjacent to the plots also was measured before beginning with the plot readings, before the plot readings were repeated, and at the end of all readings. The soil reflectance was used in the calculation of a soil-adjusted vegetative index for each plot. The vegetative indices used were the normalized difference vegetative index (NDVI) (7), the green normalized difference vegetative index (GNDVI) (9), the visible atmospherically adjusted reflectance index (VARI) (8), the difference vegetative index (DVI) (3), the renormalized difference vegetative index (RDVI) (3), and the second soil adjusted vegetative index (SAVI2) (3). Vegetative indices are analogous to statistical transformations, each having slightly different mathematical properties, which combine the information from one or more spectral bands into a single value. Indices were chosen for their ability to quantify photosynthetic leaf area and the formulas for their calculation are presented in Table 2. The reflectance bands used in the formulas were chosen to be close to the wavelengths used in the citations for each index. NDVI and DVI are classic vegetative indices with different mathematical properties that have been applied successfully to a number of different studies. RDVI is the square root of the product of NDVI and DVI and combines some of the mathematical properties of both NDVI and DVI. NDVI approaches an asymptote as leaf area increases (9), causing the sensitivity to decline as the canopy becomes dense. GNDVI was developed to overcome this lack of sensitivity. GNDVI uses the same formula as NDVI but the red band, where chlorophyll is highly absorbent, is replaced with a green band, where chlorophyll does not absorb. VARI includes a correction for atmospheric conditions, and SAVI2 includes a correction for the color of the background soil. Readings at the St. Thomas site began at 11:00 a.m. solar time and continued until 12:40 p.m. solar time (solar noon is when the sun is at zenith), with zenith angles ranging from 42 to $40^{\circ}$. Due to the high number of plots and the probability of afternoon clouds, assess- ments at the Willmar site began at 8:00 a.m. solar time and continued until 2:50 p.m. solar time. The time constraints of 11:00 a.m. to 3 p.m. Central Standard Time suggested by Guan and Nutter (10) were deemed to be too restrictive for routine use; therefore, this study emphasizes performance under real-world conditions. Zenith angles at Willmar ranged from 40 to $64^{\circ}$. At both sites, cloud cover in the afternoon prevented completion of readings during the second repeat. Radiometric measurements were stopped when irradiance dropped below 400 watts $/ \mathrm{m}^{2}$. Only 77 radiometric observations from Willmar and 10 radiometric observations from St. Thomas were available from the second evaluation to assess reproducibility. Visual evaluations without a corresponding radiometric evaluation were excluded from the assessment of reproducibility.

Analysis. Data were analyzed by analysis of variance (ANOVA) using SAS (SAS Institute, Cary, NC) which provided CVs, $F$ statistics, and the corresponding probability levels. Variance was portioned into block and treatment effects for each site. Precision was assessed by comparing the CV from different assessment methods. Sensitivity was assessed by comparing the treatment $F$ statistic from each assessment method. Reproducibility was assessed by calculating Pearson's correlation coefficient between the initial assessment with the second assessment for each method. Exploratory regression models were developed using S-Plus (Insightful Corporation, Seattle) to study the relationship between selected radiometric measures and the visual estimates of the individual raters.

\section{RESULTS}

Cercospora leaf spot severity was high at the Willmar site and moderate at St. Thomas. Visual disease assessments at the Willmar site ranged from 1.5 to 9 with a mean of 3.88 for the local rater and 1 to 9 with a mean of 4.80 for the visiting rater. At the St. Thomas site, visual disease assessments ranged from 1 to 7.5 with a mean of 4.12 for the local rater and 1 to 6.5 with a mean of 2.54 for the visiting rater. This range of disease severities provided sufficient variability to compare disease assessment methods.

The precision of each method was compared through the CVs for each assessment method. At both sites, the visiting rater had the highest CV, 30.16 at Willmar and 40.90 at St. Thomas, of any of the assessments, indicating low precision, while GNDVI had the lowest CV, 6.70 at Willmar and 2.47 at St. Thomas, indicating high precision (Table 3). The CV for each of the radiometric assessment methods was substantially lower than the CV for either of the raters at each site. The CV for yield was intermediary to the visual assessments and the radiometric methods.

The treatment $F$ statistics and corresponding probabilities from the ANOVA provided a measure of the sensitivity of each assessment method at discriminating differing levels of disease severity (Table $3)$. At the Willmar site, SAVI2 had the highest $F$ of 4.55 , though DVI at 4.53 was only slightly lower, indicating greater sensitivity. At the St. Thomas site, the local rater had the highest $F$ of 26.59 , with all other evaluations having much lower separation of treatments. Of the radiometric methods, DVI at 13.94 had the greatest $F$ at the St. Thomas site. Yield was not significantly different between treatments at the $P=0.05$ level due to low $F$ values, 1.50 at Willmar and 3.17 at St. Thomas, suggesting poor sensitivity to treatment effects. This is not surprising, because yield integrates a number of agronomic factors, resulting in high variability.

Each assessment, with the exception of yield, was repeated a second time shortly following the first evaluation. The correlation between successive assessments provided a measure of the reproducibility of each method (Table 3). At Willmar, the visiting rater and RDVI had the highest correlations $(r=0.94)$ between successive evaluations. At St. Thomas, the local rater had the highest correlation $(r=0.96)$ between successive evaluations. The vegetative indices DVI and RDVI had higher correlations ( $r=$ 0.92 ) than any of the single-waveband reflectance values at both sites.

Table 2. Vegetative indices used in this study and their method of calculation

\begin{tabular}{llc}
\hline Vegetative index $^{\mathbf{y}}$ & \multicolumn{1}{c}{ Formula $^{\mathbf{z}}$} & Reference \\
\hline NDVI & $\left(\mathrm{R}_{760}-\mathrm{R}_{710}\right) /\left(\mathrm{R}_{760}+\mathrm{R}_{710}\right)$ & 7 \\
GNDVI & $\left(\mathrm{R}_{810}-\left[\left(\mathrm{R}_{510}+\mathrm{R}_{561}\right) / 2\right]\right) /\left(\mathrm{R}_{810}+\left[\left(\mathrm{R}_{510}+\mathrm{R}_{561}\right) / 2\right]\right)$ & 9 \\
VARI & $\left(\mathrm{R}_{559}-\mathrm{R}_{661}\right) /\left(\mathrm{R}_{559}+\mathrm{R}_{661}-\mathrm{R}_{460}\right)$ & 8 \\
DVI & $\mathrm{R}_{810}-\left(\left[\mathrm{R}_{610}+\mathrm{R}_{661}\right] / 2\right)$ & 3 \\
RDVI & $\sqrt{\mathrm{NDVI} \mathrm{DVI}}$ & 3 \\
SAVI2 & $\mathrm{R}_{810} /\left(\left[\left(\mathrm{R}_{610}+\mathrm{R}_{661}\right) / 2\right]+b / a\right)$ & 3 \\
\hline
\end{tabular}

y NDVI = normalized difference vegetative index, GNDVI = green normalized difference vegetative index, VARI $=$ visible atmospherically adjusted reflectance index, DVI $=$ difference vegetative index, RDVI $=$ renormalized difference vegetative index, and SAVI $2=$ second soil adjusted vegetative index.

${ }^{\mathrm{z}}$ Reflectance at nanometers indicated (760,710, and so on). Values of $a$ and $b$ represent adjustments for the spectrum of the background soil. They were derived from bare soil readings as the slope and intercept, respectively, of a line plotted between the average reflectance of 610 and $661 \mathrm{~nm}$ and reflectance at $810 \mathrm{~nm}$. 
There was great variability within the different radiometric assessment methods. Many of the single-waveband reflectance values had very poor precision, sensitivity, and reproducibility. Single-waveband reflectance at $760 \mathrm{~nm}$, single-waveband reflectance at $810 \mathrm{~nm}$, DVI, RDVI, and SAVI2 were selected for further analysis with exploratory regression models due to their high levels of precision, sensitivity, and repeatability. The regression models using RDVI and SAVI2 had the best fits with the visual disease evaluation methods (Table 4). The results for RDVI and SAVI2 were similar; therefore, only the results from regression with RDVI are discussed further. The slopes of the regression equations (Fig. 1) were negative because RDVI increases with increasing amounts of photosynthetic leaf tissue. All of the regression models gave a good fit between RDVI and individual visual assessments, except for that of the local rater at Willmar with an adjusted $R^{2}$ of 0.30 .

Close examination of the regression data revealed a discrepancy between the evaluations from the local rater at Willmar and the local rater at St. Thomas. The slope of the regression model for the local raters was -1.2 at Willmar and -4.0 at St. Thomas, whereas the slope for the visiting rater was -2.8 at both sites. The relationship between the visiting rater's disease evaluation and RDVI stayed constant between both sites, but the two local raters had very different relationships to each other. This would suggest that the local rater at the St. Thomas site tended to give higher ratings for the same level of disease than the local rater at the Willmar site.
Cercospora leaf spot disease pressure tends to be higher in the southern region, where Willmar is located, than in the northern region, where St. Thomas is located. In addition, many past Cercospora trials in the southern region have been inoculated, resulting in higher disease pressure. The rater in the south is accustomed to seeing very severe Cercospora symptoms, whereas the rater to the north does not see severe Cercospora on a regular basis and his ratings may tend to be biased toward higher values for disease ratings.

\section{DISCUSSION}

Disease severity estimates are required for fungicide trials, cultivar trials, and the development and implementation of disease risk models. Typically, visual assessments are used to determine disease severity. Several studies have shown radiometric methods to be more precise and accurate than visual assessments across a wide range of crops $(21,23-26)$. Due to the coalescing lesions and loss of older leaves, it is difficult to measure Cercospora leaf spot accurately. Sherwood et al. (28) found that visual estimates of disease tended to overestimate when the infected area was small or when lesions were small and numerous. On the other hand, the vegetative indices used in this study largely are affected by the percentage of photosynthetically active tissue present in the field of view of the radiometer. We chose to compare radiometric evaluation methods with visual assessments based on precision, sensitivity to fungicide treatment differences, and reproducibility. In the absence of a method universally regarded as accurate, sensitivity can act as a surrogate measure and, unlike accuracy, sensitivity is easily quantified with effective fungicide treatments and sufficient disease pressure. For routine disease evaluations, the time required for evaluations and the ease of performing evaluations also are important considerations. An ideal disease assessment method would be accurate, precise, and reproducible, free from potential bias, and could be performed with minimal training. Mechanical methods, such as measurements with a radiometer, tend to be reproducible and less prone to human bias.

Table 4. Coefficients of determination $\left(R^{2}\right)$ for regressions of selected radiometric assessment methods against visual disease assessments

\begin{tabular}{lccccc}
\hline & \multicolumn{2}{c}{ Willmar } & & \multicolumn{2}{c}{ St. Thomas } \\
\cline { 2 - 3 } \cline { 5 - 6 } Assessment method $^{\mathbf{z}}$ & Local rater & Visiting rater & & Local rater & Visiting rater \\
\hline $\mathrm{R}_{760}$ & 0.28 & 0.74 & & 0.56 & 0.55 \\
$\mathrm{R}_{810}$ & 0.29 & 0.75 & & 0.56 & 0.55 \\
$\mathrm{DVI}$ & 0.29 & 0.77 & & 0.60 & 0.60 \\
RDVI & 0.30 & 0.79 & & 0.68 & 0.70 \\
SAVI2 & 0.30 & 0.78 & & 0.69 & 0.70 \\
\hline
\end{tabular}

${ }^{\mathrm{z}} \mathrm{R}=$ reflectance at nanometers indicated $(760$ and 810$)$, DVI $=$ difference vegetative index, RDVI $=$ renormalized difference vegetative index, and SAVI2 = second soil adjusted vegetative index.

Table 3. The precision, measured by coefficient of variation (CV); sensitivity, measured by treatment $F$; and reproducibility, measured by correlation between multiple assessments, of visual and radiometric assessment methodsw

\begin{tabular}{|c|c|c|c|c|c|c|}
\hline \multirow[b]{2}{*}{ Assessment method $^{x}$} & \multicolumn{3}{|c|}{ Willmar } & \multicolumn{3}{|c|}{ St. Thomas } \\
\hline & $\mathbf{C V}$ & $F_{\text {tmt }}, P^{y}$ & $r_{\text {pearson }} \mathrm{z}$ & $\mathbf{C V}$ & $F_{\text {tmt }}, P^{y}$ & $r_{\text {pearson }} \mathrm{z}$ \\
\hline Local rater & 26.85 & $3.38\left(1.27 \times 10^{-05}\right)$ & 0.85 & 19.63 & $26.59\left(6.94 \times 10^{-06}\right)$ & 0.96 \\
\hline Visiting rater & 30.16 & $4.38\left(1.67 \times 10^{-07}\right)$ & 0.94 & 40.90 & $4.87\left(1.45 \times 10^{-02}\right)$ & 0.93 \\
\hline $\mathrm{R}_{460}$ & 9.40 & $1.53\left(7.06 \times 10^{-02}\right)$ & 0.22 & 6.81 & $2.71\left(8.11 \times 10^{-02}\right)$ & 0.44 \\
\hline $\mathrm{R}_{510}$ & 13.03 & $1.02\left(4.56 \times 10^{-01}\right)$ & 0.34 & 3.15 & $2.86\left(7.09 \times 10^{-02}\right)$ & 0.51 \\
\hline $\mathrm{R}_{559}$ & 11.37 & $2.31\left(1.93 \times 10^{-03}\right)$ & 0.60 & 6.25 & $2.54\left(9.45 \times 10^{-02}\right)$ & 0.52 \\
\hline $\mathrm{R}_{610}$ & 9.65 & $1.47\left(9.22 \times 10^{-02}\right)$ & 0.28 & 7.95 & $1.04\left(4.29 \times 10^{-01}\right)$ & 0.63 \\
\hline $\mathrm{R}_{661}$ & 8.76 & $1.31\left(1.72 \times 10^{-01}\right)$ & 0.08 & 8.39 & $2.10\left(1.43 \times 10^{-01}\right)$ & 0.59 \\
\hline $\mathrm{R}_{710}$ & 11.10 & $2.15\left(4.24 \times 10^{-03}\right)$ & 0.53 & 6.52 & $1.94\left(1.69 \times 10^{-01}\right)$ & 0.60 \\
\hline $\mathrm{R}_{760}$ & 15.29 & $4.26\left(2.82 \times 10^{-07}\right)$ & 0.89 & 6.55 & $13.69\left(2.00 \times 10^{-04}\right)$ & 0.90 \\
\hline $\mathrm{R}_{810}$ & 14.54 & $4.45\left(1.28 \times 10^{-07}\right)$ & 0.90 & 6.19 & $13.89\left(1.86 \times 10^{-04}\right)$ & 0.91 \\
\hline $\mathrm{R}_{935}$ & 15.72 & $3.51\left(6.93 \times 10^{-06}\right)$ & 0.68 & 6.03 & $11.00\left(5.53 \times 10^{-04}\right)$ & 0.81 \\
\hline NDVI & 7.74 & $3.74\left(2.53 \times 10^{-06}\right)$ & 0.88 & 4.68 & $5.90\left(7.32 \times 10^{-03}\right)$ & 0.92 \\
\hline GNDVI & 6.70 & $3.52\left(6.64 \times 10^{-06}\right)$ & 0.88 & 2.47 & $6.98\left(3.84 \times 10^{-03}\right)$ & 0.85 \\
\hline VARI & 11.90 & $3.05\left(5.88 \times 10^{-05}\right)$ & 0.92 & 4.17 & $10.01\left(8.45 \times 10^{-04}\right)$ & 0.88 \\
\hline DVI & 16.05 & $4.53\left(9.26 \times 10^{-08}\right)$ & 0.91 & 6.81 & $13.94\left(1.83 \times 10^{-04}\right)$ & 0.92 \\
\hline RDVI & 11.66 & $4.45\left(1.24 \times 10^{-07}\right)$ & 0.94 & 5.34 & $11.89\left(3.88 \times 10^{-04}\right)$ & 0.92 \\
\hline SAVI2 & 13.06 & $4.55\left(8.36 \times 10^{-08}\right)$ & 0.89 & 7.13 & $10.07\left(8.24 \times 10^{-04}\right)$ & 0.87 \\
\hline Yield & 18.54 & $1.50\left(8.11 \times 10^{-02}\right)$ & $\ldots$ & 8.25 & $3.17\left(5.41 \times 10^{-02}\right)$ & $\ldots$ \\
\hline
\end{tabular}

${ }^{w}$ Due to differences in degrees of freedom, $F$ statistics are comparable only within a single column. Willmar had 33 numerator degrees of freedom and 66 denominator degrees of freedom, whereas St. Thomas had 4 and 12, respectively.

${ }^{\times} \mathrm{R}=$ reflectance at nanometers indicated $(460,510$, and so on), NDVI = normalized difference vegetative index, GNDVI $=$ green normalized difference vegetative index, VARI = visible atmospherically adjusted reflectance index, DVI = difference vegetative index, RDVI = renormalized difference vegetative index, and SAVI2 = second soil adjusted vegetative index.

${ }^{\text {y }} F$ statistics for the treatment effect from an analysis of variance; numbers in parentheses are the associated probabilities of a lower $F$.

${ }^{z}$ Pearson's correlation coefficients with an absolute value below 0.22 at Willmar and 0.63 at St. Thomas are not significant at the $P=0.05$ level. Due to afternoon cloud cover, only 77 observations were available from Willmar and 10 from St. Thomas. 
As noted in previous studies $(23,28)$, visual diseases assessments of Cercospora leaf spot severity suffered from low precision. With the exception of the assessments by the local rater at St. Thomas, visual disease assessments were not as sensitive to treatment differences as the best radiometric methods. Disease assessment is a skill that must be learned (22), and some individuals are more skilled than others (28). While Shokes et al. (29) defined reproducibility as the correlation between repeated evaluations of the same rater, Campbell and Madden (6) defined reproducibility as the lack of variance among evaluators assessing the same samples. In this study, we measured reproducibility by the test-retest method of Shokes et al. (29). When considering reproducibility as defined by Campbell and Madden, visual evaluations at the Willmar site were not reproducible between the two raters. At the St. Thomas site, the two raters had high correlation because the slopes of the regression models were similar, but there was a systematic bias, with the local rater giving higher disease levels than the visiting rater. In addition, as noted in the results, there appeared to be a discrepancy between the local raters at the two sites. These observations suggest that their visual evaluations were not reproducible as defined by Campbell and Madden. The relationship between the visiting rater and RDVI remained constant over 2 days at two different sites.

The vegetative indices varied in their precision, reproducibility, and sensitivity. Single-waveband reflectance in the visible region of the spectrum, from $710 \mathrm{~nm}$ and lower, suffered from poor reproducibility and a lack of sensitivity. The best radiometric measures, based on precision, sensitivity, and reproducibility, appeared to be the single-waveband reflectance values at 760 and $810 \mathrm{~nm}$, DVI, RDVI, and SAVI2. The differences among these measures were not sufficiently great to choose one method over another. The choice of radiometric method is not critical, because most radiometers gather all of the singlewaveband reflectance data simultaneously, and vegetative indices are calculated later as part of data analysis. At least one vegetative index always gave a higher level of precision, sensitivity, and reproducibility than the single-waveband reflectance values at 760 and $810 \mathrm{~nm}$, warranting their calculation before statistical analysis. The variation between the individual vegetative indices is related to their mathematical properties. The vegetative index DVI has been shown to have low error with dense canopies, whereas NDVI has low error with sparse canopies (3). RDVI is a combination of these two vegetative indices; therefore, it performed well in the Broge and Leblanc study (3) over a wide range of canopy densities. Several studies have shown vegetative indices tended to work better than single-waveband reflectance data $(2,17,20)$. In contrast, Nilson (18) found that single-waveband reflectance values worked better for wheat tan spot and one set of readings with take-all of wheat, whereas ratios of wavebands gave better results during the second set of readings. Our data support this mix of results. Evaluations with vegetative indices require simple calculations, based on single-waveband reflectance data, which are easily performed in the same manner as statistical transformations. Future researchers would be wise to consider both methods after the time and effort of gathering the radiometric data, rather than focusing on vegetative indices or single-waveband reflectance data alone.

Radiometric methods are not without their limitations. For the radiometric data to be repeatable, sunny conditions are required. As noted in Materials and Methods, we were unable to complete all of the scans in the second evaluation due to afternoon clouds. A radiometer that provides its own light source, such as the GreenSeeker (NTech Industries, Inc, Ukiah, CA), can be used under any weather conditions and would be preferable for routine use. The radiometer also took almost three times as long as visual assessments. Using the methods described for this study, radiometers do not measure disease directly but measure the amount of photosynthetic tissue present in the field of view of the radiometer. It is necessary for the radiometer operator to verify that differences among plots are due to disease and not other factors, such as weeds or unequal plant populations, because these also would affect radiometric readings.

This study has shown that radiometric disease evaluations can be used effectively to measure necrosis caused by Cercospora leaf spot. Past studies utilizing radiometers for disease assessment have shown them to be reproducible across days and sites $(10,23,24)$. The high precision and sensitivity of this method will be useful for the development and improvement of predictive models, where errors in assessments directly reduce the predictive power of the model. In addition, this method reduces the chance of biased readings, which growers favor when proprietary material is being assessed. Because the radiometer cannot discriminate between defoliation caused by disease and defolia-

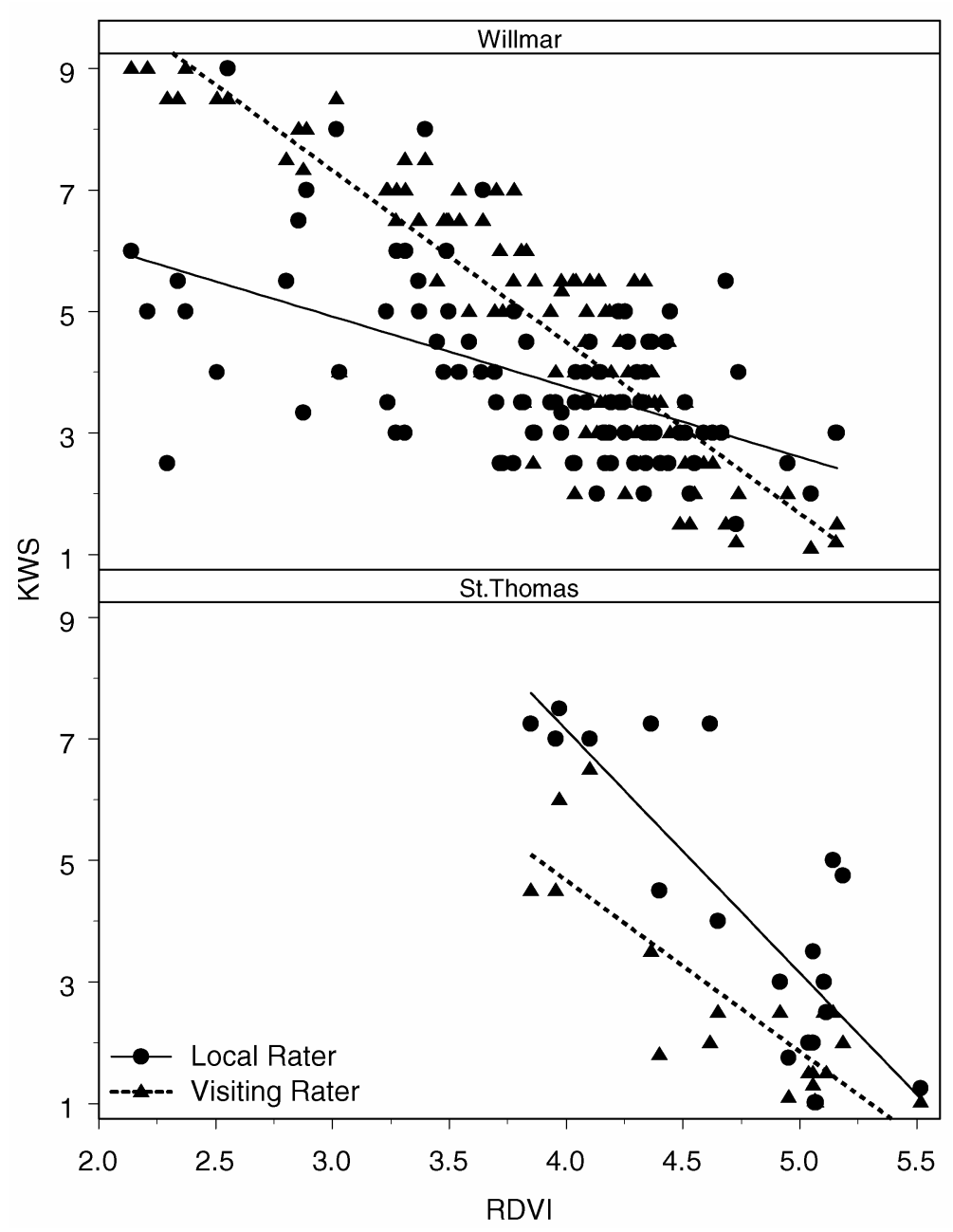

Fig. 1. Visual estimates of Cercospora leaf spot severity regressed against the radiometric assessment, renormalized difference vegetative index. 
tion from other sources, the authors do not recommend eliminating visual disease estimates. Frequent radiometric readings by technical staff with occasional visual evaluations by trained disease evaluators can maximize the strengths of both methods. Additional studies will be required to assess the utility of newer radiometers such as the GreenSeeker to overcome problems with cloud cover and to evaluate repeatability over time and between sites. Because Cercospora appears to be uniformly distributed across fields, it is unlikely that this could be used for sitespecific application of fungicides; however, the methods used could be applied to other diseases where site-specific methods are more suited.

\section{LITERATURE CITED}

1. Baret, F., and Guyot, G. 1991. Potentials and limits of vegetation indices for LAI and APAR assessment. Remote Sens. Environ. 35:161173.

2. Blazquez, C. H., and Edwards, G. J. 1986. Spectral reflectance of healthy and diseased watermelon leaves. Ann. Appl. Biol. 108:243-249.

3. Broge, N. H., and Leblanc, E. 2000. Comparing prediction power and stability of broadband and hyperspectral vegetation indices for estimation of green leaf area index and canopy chlorophyll density. Remote Sens. Environ. 76:156-172.

4. Bugbee, W. M. 1982. Sugarbeet disease research-1981. 1981 Sugarbeet Res. Ext. Rep. N. D. State Univ. 12:155

5. Bugbee, W. M., Nielsen, G., and Sundsbak, J. 1995. A survey for the prevalence and distribution of Cercospora beticola tolerant to triphenyltin hydroxide and resistant to thiophanate methyl in Minnesota and North Dakota-1995. 1995 Sugarbeet Res. Ext. Rep. N. D. State Univ. 26:176-178.

6. Campbell, C. L., and Madden, L. V. 1990. Page 111 in: Introduction to Plant Disease Epidemiology. John Wiley \& Sons, New York.

7. Gamon, J. A., and Surfus, J. S. 1999. Assessing leaf pigment content and activity with a reflectometer. New Phytol. 143:105-117.

8. Gitelson, A. A., Kaufman, Y. J., Stark, R., and Rundquist, D. 2002. Novel algorithms for remote estimation of vegetation fraction. Re- mote Sens. Environ. 80:76-87.

9. Gitelson, A. A., and Merzlyak, M. N. 1997. Remote estimation of chlorophyll content in higher plant leaves. Int. J. Remote Sens. 18:2691-2697.

10. Guan, J., and Nutter, F. W., Jr. 2001. Factors that affect the quality and quantity of sunlight reflected from alfalfa canopies. Plant Dis. 85:865-874.

11. Jackson, R. D. 1986. Remote sensing of biotic and abiotic plant stress. Annu. Rev. Phytopathol. 24:265-287.

12. Khan, M., and Cattanach, N. 2002. Managing Cercospora leaf spot in sugarbeet using the Cercospora leaf spot prediction model. 2001 Sugarbeet Res. Ext. Rep. N. D. State Univ. 32:311-316.

13. Khan, J., and Khan, M. 2003. Validating the Cercospora prediction model as a decision making tool for managing Cercospora leaf spot in sugarbeet. 2002 Sugarbeet Res. Ext. Rep. N. D. State Univ. 33:247-253.

14. Khan, M., Smith, L., Bredehoeft, M., and Roehl, S. 2001. Cercospora leaf spot control in Eastern North Dakota and Minnesota in 2000. 2000 Sugarbeet Res. Ext. Rep. N. D. State Univ. 32:303-310.

15. Khan, M., Smith, L., Bredehoeft, M., and Roehl, S. 2003. Cercospora leaf spot control in Eastern North Dakota and Minnesota in 2002. 2002 Sugarbeet Res. Ext. Rep. N. D. State Univ. 33:223-230.

16. Kleinwanzleber Saatzucht Ag. Einbeck. 1970. Cercospora. Kleinwanzleber Saatzucht Ag. Einbeck Rabbethge and Giesecke.

17. Kobayashi, T., Kanda, E., Kitada, K., Ishiguro, K., and Torigoe, Y. 2001. Detection of rice panicle blast with multispectral radiometer and the potential of using airborne multispectral scanners. Phytopathology 91:316-323.

18. Nilsson, H.-E. 1991. Hand-held radiometry and IR-thermography of plant diseases in field plot experiments. Int. J. Remote Sens. 12:545557.

19. Nilsson, H.-E. 1995. Remote sensing and image analysis in plant pathology. Annu. Rev. Phytopathol. 15:489-527.

20. Nilsson, H.-E., and Johnson, L. 1996. Handheld radiometry of barley infected by barley stripe disease in a field experiment. Z. Pflanzenkrankh. Pflanzenschutz 103:517-526.

21. Nutter, F. W., Jr. 1989. Detection and measurement of plant disease gradients in peanut with a multispectral radiometer. Phytopathology 79:958-963.
22. Nutter, F. W., Jr. 1997. Disease severity assessment training. Pages 1-7 in: Exercises in Plant Disease Epidemiology. L. J. Francl and D. A. Neher, eds. American Phytopathological Society Press, St. Paul, MN

23. Nutter, F. W., Jr., Gleason, M. L., Jenco, J. H., and Christians, N. C. 1993. Assessing the accuracy, intra-rater repeatability, and inter-rater reliability of disease assessment systems. Phytopathology 83:806-812.

24. Nutter, F. W., Jr., Guan, J., Gotlieb, A. R., Rhodes, L. H., Grau, C. R., and Sulc, R. M. 2002. Quantifying alfalfa yield losses caused by foliar diseases in Iowa, Ohio, Wisconsin, and Vermont. Plant Dis. 86:269-277.

25. Nutter, F. W., Jr., Littrell, R. H., and Brenneman, T. B. 1990. Utilization of a multispectral radiometer to evaluate fungicide efficacy to control late leaf spot in peanut. Phytopathology 80:102-108.

26. Raikes, C., and Burpee, L. L. 1998. Use of multispectral radiometry for assessment of Rhizoctonia blight in creeping bentgrass. Phytopathology 88:446-449.

27. Sharp, E. L., Perry, C. R., Scharen, A. L., Boatwright, G. O., Sands, D. C. Lauterschlager, L. F., Yahyaoui, C. M., and Ravet, F. W. 1985. Monitoring cereal rust development with a spectral radiometer. Phytopathology 75:936-939.

28. Sherwood, R. T., Berg, C. C., Hoover, M. R. and Zeiders, K. E. 1983. Illusions in visual assessment of Stagonospora leaf spot of orchardgrass. Phytopathology 73:173-177.

29. Shokes, F. M., Berger, R. D., Smith, D. H., and Rasp, J. M. 1987. Reliability of disease assessment procedures: A case study with late spot of peanut. Oleagineux 42:245-251.

30. Steddom, K., Heidel, G., Jones, D., and Rush, C. M. 2003. Remote detection of rhizomania in sugar beets. Phytopathology 93:720-726.

31. Steele, R. G. D., and Torrie, J. H. 1980. Page 633 in: Principles and Procedures of Statistics: A Biometrical Approach, Second ed. McGrawHill, Inc., New York.

32. Weiland, J. J. 2003. A survey for the prevalence and distribution of Cercospora beticola tolerant to triphenyltin hydroxide and resistant to thiophanate methyl in 2002. 2002 Sugarbeet Res. Ext. Rep. N. D. State Univ. 33:241-246.

33. Windels, C. E., Lamey, H. A., Hilde, D., Widner, J., and Knudsen, T. 1998. A Cercospora leaf spot model for sugar beet: in practice by an industry. Plant Dis. 82:716-726. 